\title{
QUALIDADE DE SEMENTES DE ACESSOS DE MELÃO CRIOULO (Cucumis melo L.) ${ }^{1}$
}

\author{
ANDRÉABECKER DELWING ${ }^{2}$, LÚCIABRANDÃO FRANKE ${ }^{3}$, INGRID BERGMAN INCHAUSTIDEBARROS ${ }^{4}$
}

\begin{abstract}
RESUMO - O estudo avaliou a qualidade de sementes de seis acessos de melões crioulos (Cucumis melo L.), oriundos de propriedades de agricultores familiares de diferentes regiões do estado do Rio Grande do Sul. Os ensaios experimentais foram realizados no Laboratório de Análise de Sementes do Ministério da Agricultura (LASO/LANAGRO-RS) e no Laboratório de Sementes do Departamento de Plantas Forrageiras e Agrometereologia da Faculdade de Agronomia da UFRGS. As sementes de cada acesso foram avaliadas quanto a coloração e dimensão e submetidas às seguintes determinações: peso de mil sementes, germinação, primeira contagem de germinação, índice de velocidade de germinação, peso seco das plântulas, tamanho das plântulas e envelhecimento acelerado e sanidade. Todos os acessos apresentaram mais de $80 \%$ de germinação, independente das condições de manejo pós-colheita e armazenamento. As sementes dos acessos de melões tradicionais apresentaram variações significativas na coloração e dimensões. Os testes sanitários não indicaram a presença de vírus ou bactérias nos acessos, embora tenha sido observada a presença dos fungos Phoma sp., Cladosporium sp. e Fusarium sp.
\end{abstract}

Termos para indexação: germinação, agricultura tradicional, variedades crioulas.

\section{QUALITY OF LANDRACE MELON SEEDS (Cucumis melo L.)}

\begin{abstract}
This study aimed to evaluate the quality of seeds from six landrace melon (Cucumis melo L.) accessions, obtained from family farms across different zones in the state of Rio Grande do Sul. The assays were carried out in the Seed Analysis Laboratory, Ministry of Agriculture (LASO/ LANAGRO-RS), and in the Seed Laboratory Department of Forage Plants and Agrometeorology, Faculty of Agronomy, Federal University of Rio Grande do Sul (UFRGS). Samples were evaluated by the weight of one thousand seeds, germination test, first count, germination speed index, seedling dry weight, seedling size and accelerated aging test. The seeds of traditional melon accessions showed significant variation in color and size. All the accessions had more than $80 \%$ germination, regardless of post-harvest and storage management, indicating that the use of these varieties can be increased. The accelerated aging test did not permit ranking of the seed vigor level. Sanitary tests did not reveal viruses or bacteria in the seeds investigated, although Phoma sp., Cladosporium sp. and Fusarium sp. were detected in some accessions.
\end{abstract}

Index terms: germination, traditional agriculture, landraces.

\section{INTRODUÇÃO}

As variedades tradicionais, crioulas ou landraces são cada vez mais motivo de estudos, principalmente por constituírem fonte de alelos em relação à estreita base genética das

\footnotetext{
${ }^{1}$ Submetido em 04/05/2006. Aceito para publicação em 24/05/2007. Parte da Dissertação de Mestrado da prmeira autora apresentada à UFRGS.

${ }^{2}$ Bióloga, Mestre em Fitotecnia, Dep. de Horticultura da Faculdade de Agronomia da Universidade Federal do Rio Grande do Sul - UFRGS. Rua Ney da Gama Ahrends, 179/casa 21. Bairro Protásio Alves - 91450345/
}

variedades modernas. As variedades crioulas podem ser definidas como variedades tradicionais de plantas cultivadas, adaptadas aos locais e culturas onde se desenvolveram, estando presentes nos bancos de sementes de muitos agricultores, principalmente em países em desenvolvimento,

Porto Alegre-RS. abdelwing@terra.com.br . Apoio financeiro: CNPq

${ }^{3}$ Eng. Agrônoma, Dra, Prof. Adj. do Departamento de Plantas Forrageiras e Agrometereologia / UFRGS.

${ }^{4}$ Eng. Agrônoma, Dra, Prof. Tit. do Departamento de Horticultura e Silvicultura / UFRGS 
justamente por se constituírem como uma garantia de plantio no ano seguinte. A 'adaptabilidade' conferida às variedades tradicionais se manifesta como uma maior estabilidade e segurança nos rendimentos dos agricultores de subsistência, sendo por isto as variedades preferidas por estes (Dominguez et al., 2000).

Uma das famílias botânicas com um grande número de espécies cultivadas, apresentando variedades tradicionais, é a Cucurbitaceae. Dentre as espécies de Cucurbitaceae com uma riqueza de variedades tradicionais estão as abóboras (Cucurbita spp.), melancias (Citrulus lanatus (Thunb) Mansf) os melões (Cucumis melo L.), entre outras. O melão (C. melo L.) é uma espécie que ainda apresenta variedades tradicionais mantidas por muitos agricultores de subsistência de diferentes regiões do planeta (Kokopeli, 2005).

Dentre as regiões apontadas como originárias da domesticação da espécie, pode-se encontrar aquelas que, além das variedades tradicionais, também apresentam variedades silvestres de melões, como no Sudão, além de vários outros países africanos. Regiões como estas seriam denominadas 'Centros Primários de Domesticação', sendo regiões de grande relevância quanto à variabilidade da espécie (Mohamed e Taha Yousif, 2004). De uma forma geral, há referências de centros de cultivo secundários da China à Tailândia, Burma e Índia (Pitrat et al., 2000), regiões para onde os cultivos iniciais possivelmente tenham se estendido.

De acordo com Mohamed e Taha Yousif (2004), C. melo é mais polimórfica que outras espécies de seu gênero. Tal polimorfismo é maior em relação às características de seus frutos. Devido a tais características, tem havido muitas tentativas de subdividir taxonomicamente os melões cultivados em subespécies e variedades ou grupos botânicos, tarefa que vem sendo desenvolvida por muitos pesquisadores nos últimos anos como Munger e Robinson (1991) e Pitrat et al., (2000).

A espécie C. melo, apesar de ter seus centros de origem, domesticação primária e secundária em regiões distantes do Brasil, apresenta variedades adaptadas aos agroecossistemas brasileiros. De acordo com Tavares (2002), as variedades tradicionais de melões no Brasil apresentam grande variação morfológica, inclusive com resistência ao oídio, e têm sido identificadas na agricultura tradicional do Nordeste (Tavares, 2002).

Em relação ao Rio Grande do Sul, apesar da introdução de um grande número de variedades melhoradas e híbridas da espécie nos últimos anos, ainda existem variedades crioulas resultantes de inúmeros ciclos de seleção realizados durante gerações por agricultores familiares. Tavares (2002) indica as regiões Sul e Sudeste como aquelas em que o melão foi introduzido desde o século XVI através da imigração, sugerindo assim a existência de acessos de mais de 400 anos nessas regiões do Brasil.

Sendo o sistema informal de sementes o grande responsável pela manutenção de muitas variedades da espécie ainda nos dias de hoje, através da conservação in situ, a avaliação da qualidade de suas sementes torna-se fundamental para que seja incentivada a promoção do seu uso, seja como estratégia de manutenção da variabilidade ou como recurso a uma agricultura auto sustentada.

O presente trabalho objetivou determinar a qualidade das sementes dos acessos de melão crioulo oriundas de propriedades de agricultores familiares de diferentes regiões do Rio Grande do Sul.

\section{MATERIAL E MÉTODOS}

Para a obtenção do material experimental foram utilizados métodos etnográficos de pesquisa. Os municípios e localidades foram selecionados a partir de contato com instituições públicas, privadas, movimentos sociais e organizações não governamentais (ONGs). O levantamento iniciou com visitas aos conhecidos 'sementeiros' de cada localidade, ou seja, agricultores que mantêm em suas propriedades um considerável banco de sementes de plantas cultivadas tradicionais. O levantamento priorizou a diversificação regional e étnica, sendo realizado em treze propriedades de oito municípios de diferentes regiões do Estado do Rio Grande do Sul. Através da metodologia 'bola de neve’ (Bernard, 1988), foram identificados novos informantes chave em cada um dos municípios e localidades contatadas. Das propriedades amostradas, dez possuíam variedades tradicionais de melão, e em seis delas coletaram-se amostras de sementes de melões crioulos em número mínimo suficiente estipulado (800 a 1000 sementes por acesso) para a realização das avaliações físicas, fisiológicas e sanitárias.

Em função do número limitado de sementes da maioria dos acessos, os testes realizados tiveram o número de repetições ou quantidade de sementes por repetição reduzido, a fim de que houvesse sementes disponíveis para todas as avaliações pretendidas. Os acessos foram oriundos dos seguintes municípios: Porto Alegre (acesso 1); Ipê (acesso 2); Antônio Prado (acesso 3); Bom Retiro do Sul (acesso 4); Santo Antônio do Palma (acessos 5 e 6). Para facilitar a identificação, os acessos foram numerados de acordo com a ordem de coleta (de 1 a 6 ). O número foi seguido de uma 
letra ( $\mathrm{N}$ ou $\mathrm{D})$, conforme denominações utilizadas pelos agricultores às variedades de melões: $\mathrm{N}$ - melões tipo 'neve' e D- melões tipo ‘doce’. Foi utilizado como parâmetro para as avaliações realizadas um lote de sementes de melão de polinização aberta, do tipo varietal Caipira ${ }^{a}$ cedido pela empresa ISLA Sementes Ltda., situada em Porto Alegre/RS, sendo identificado como testemunha (T).

Após a conclusão de todas as coletas, as análises foram realizadas no Laboratório Oficial de Análise de Sementes do Ministério da Agricultura, Pecuária e Abastecimento (LASO/ LANAGRO-RS) e no Laboratório de Sementes do Departamento de Plantas Forrageiras e Agrometereologia da Faculdade de Agronomia da UFRGS, durante os meses de abril a junho de 2005. Até o momento das avaliações, as sementes dos acessos permaneceram em recipientes plásticos fechados, sob temperatura de $5^{\circ} \mathrm{C}$.

Para a padronização dos materiais, foi realizada a remoção de sementes vazias ou conhecidas popularmente como “chochas”, constituídas só de tegumento, através de separador de gravidade, antes da realização dos testes, procedimento realizado com a amostra comercial que serviu como parâmetro às avaliações.

Das sementes das amostras coletadas e da cultivar comercial foram retiradas subamostras de 25 sementes de cada lote, obtidas através de subdivisões consecutivas realizadas com o auxílio de um divisor de sementes, tipo divisor de solo. As subamostras de cada lote de sementes foram avaliadas quanto às características de comprimento e largura (C/L), além da determinação do coeficiente de variação. A coloração e as dimensões foram também avaliadas e registradas por meio de fotografias e paquímetro.

Em seguida, as sementes foram submetidas aos seguintes testes e determinações: pureza física $(P)$, grau de umidade (GU), peso de mil sementes (PMS) e germinação (G), realizados conforme as Regras para Análise de Sementes RAS (Brasil, 1992) e Internacionais (ISTA, 2004).

O grau de umidade (GU) foi determinado a partir de duas amostras de 2 g cada, variando no número de sementes, dependendo de cada acesso. As sementes foram acondicionadas em recipientes metálicos, pesadas e colocadas em estufa a $105^{\circ} \mathrm{C} \pm 3^{\circ} \mathrm{C}$, por 24 horas. A seguir, procedeu-se nova pesagem das amostras. Procedeu-se o cálculo do grau de umidade conforme descrito nas RAS (Brasil, 1992).

O teste de germinação ( $G$ ) foi conduzido utilizando-se quatro repetições de 25 sementes de cada acesso e a variedade comercial (T). Seguiu-se um aspecto metodológico descrito em ISTA (2004), que sugere a utilização de medidas alternativas quando a aeração ou outros procedimentos necessários para a realização de determinados testes, como no caso particular em que se pretendia, além do acompanhamento da germinação, realizar contagens diárias. Desta forma, a semeadura foi feita em papel toalha Germitest, utilizando-se o método de papel plissado ou sanfonado, umedecido com quantidade de água destilada equivalente a 2,5 vezes o peso seco. As sementes foram acomodadas em germinadores à $25^{\circ} \mathrm{C}$. As avaliações foram realizadas no quarto e oitavo dia após a semeadura, conforme Brasil (1992) e ISTA (2004), e os resultados foram expressos em porcentagem média de plântulas normais.

A primeira contagem de germinação (PCG) foi conduzida concomitantemente ao teste de germinação, computando-se a porcentagem de plântulas normais germinadas aos quatro dias após a semeadura, sendo os resultados expressos em porcentagem de plântulas normais obtidas.

O índice de velocidade de germinação (IVG), tamanho médio das plântulas (TMP) e peso seco total (PST) também foram avaliações de vigor realizadas juntamente com o teste de germinação.

A verificação do TMP foi realizada ao final do ensaio através de registros das dimensões das plântulas normais (de acordo com as características morfológicas e tamanho mínimo estipulado), com o auxílio de um paquímetro digital. Foram medidos, separadamente, os hipocótilos (TMH) e a raiz (TMR). Através do cálculo da média aritmética das repetições foi obtido o valor do comprimento médio do lote. Para a obtenção do PST, os cotilédones e hipocótilos foram colocados separadamente em sacos de papel, em estufa a $70^{\circ} \mathrm{C}$ por $72 \mathrm{~h}$. As amostras foram retiradas e colocadas para resfriar em dessecador, sendo, em seguida, pesadas em balança de precisão 0,0001g para determinação do peso seco dos cotilédones (PSC) e das plântulas (PSP). O procedimento prosseguiu até o dia da última contagem.

Para a determinação do IVG, realizaram-se avaliações diárias das plântulas, sempre no mesmo horário do dia. Foi estipulado, anteriormente, um padrão de tamanho para o que se consideraria como plântula normal, no caso $4,5 \mathrm{~cm}$. A identificação de plântulas normais foi obtida com o auxílio de uma régua, além da observação de outras características morfológicas, como deformidades ou necroses presentes nos hipocótilos ou cotilédones, durante todos os dias de duração do ensaio (8 dias). Ao final do teste, com os dados diários do número de plântulas normais, calculou-se a velocidade de germinação, empregando-se fórmulas, como a de Maguire (1962), apresentado por Vieira e Carvalho (1994). 
Envelhecimento acelerado (EA), utilizou-se a metodologia do gerbox adaptado, desenvolvido por McDonald e Phaneendranath (1978), citada pela AOSA(1983). O método propõe a utilização de caixas plásticas gerbox como compartimento individual (mini-câmaras) para a acomodação das amostras submetidas ao teste. Foi usado o gerbox adaptado, onde 105 sementes foram distribuídas em camada única sobre tela de alumínio acoplada ao gerbox, contendo, ao fundo, $40 \mathrm{~mL}$ de água. Os gerbox foram tampados e mantidos em BOD a temperatura de $41^{\circ} \mathrm{C}$ por 72 horas (Torres, 2002). Após este período, as sementes foram colocadas para germinar em substrato de areia conforme as RAS (Brasil, 1992). Os resultados foram expressos pela porcentagem de plântulas normais $(G)$, plântulas anormais (A), e sementes não germinadas (NG).

Amostras de 110 sementes de cada acesso e da testemunha foram encaminhadas ao Departamento de Fitossanidade da UFRGS para detecção da presença de fitopatógenos. Foi realizado um exame direto em microscópio estereoscópio e incubação das sementes, em número de 100, em câmara úmida (gerbox); inoculação em meio de cultura carbonato-de-cálcio-dextrose-extrato-de-levedura (CCDEL); inoculação em plântulas e identificação das estruturas observadas. O experimento foi conduzido em delineamento completamente casualizado, com quatro repetições. Foram realizadas análises de variância para cada teste e a comparação das médias foi múltipla, pelo teste de Tukey, ao nível 5\% de probabilidade. Para os cálculos utilizou-se o programa estatístico SPSS v. 8.0.

\section{RESULTADOS E DISCUSSÃO}

Em relação à pureza física, os acessos apresentaram, na maior parte dos casos, apenas traços de material inerte. No caso do acesso $5 \mathrm{D}$, houve a detecção de sementes de outras culturas, como sementes de melancia (Citrullus lanatus), mas em quantidade inferior a 5\%, máximo estabelecido nas RAS (Brasil, 1992). Tais dados sugerem a existência de cuidados por parte dos agricultores a fim de evitar misturas durante o manejo com sementes de diferentes espécies. No entanto, a presença de misturas físicas está mais relacionada com medidas estabelecidas em legislação como parâmetro para a comercialização, não havendo, em função de tais misturas, quaisquer interferências na pureza genética do material. Por outro lado, parâmetros oficialmente estabelecidos que reconheçam e garantam a qualidade genética das variedades tradicionais, não existem.

Houve diferença no tamanho médio e coloração entre as sementes de melões tipo 'neve' e tipo ‘doce'. As sementes dos acessos conhecidos como 'neve', na maior parte dos casos, foram mais claras e de menor tamanho. Embora tenha sido atribuída a característica 'neve' ao acesso $6 \mathrm{~N}$, a morfologia das sementes não mostrou semelhança em relação a outros acessos 'neve', possuindo características dos acessos conhecidos como ‘doces' (Tabela 1).

O PMS variou de 19,24 a 37,86 g, salientando que o coeficiente de variação (CV) dos diferentes acessos e a testemunha foi de 22,33\%, indicando alta heterogeneidade entre os acessos quanto ao peso de sementes. Comparandose o CV entre os acessos da mesma variedade, a variação foi muito alta nos acessos de melões tipo "neve”, com CV de 33,07\%, e média para melões tipo “doce”, cujo CV foi de 18,97\%. Ao analisar-se o coeficiente de variação em relação a cada um dos acessos (Tabela 2), foram verificados valores relativamente baixos, com maior valor para o acesso 6 (6,9\%).

Ainda em relação às características físicas, apesar de ter sido mencionada a prática da higienização antes da armazenagem, as sementes do acesso $2 \mathrm{~N}$ estavam cobertas pela massa liquefeita da polpa sucosa na qual estão embebidas, caracterizando manejo pós-colheita ausente ou deficiente, havendo um grande percentual de sementes vazias (Tabela 2). Segundo o agricultor mantenedor de tal acesso, o grande

TABELA 1. Características físicas das sementes de melões crioulos de seis acessos e testemunha. UFRGS, Porto Alegre/ RS, 2006.

\begin{tabular}{|c|c|c|c|c|c|}
\hline Acesso & Cor & $\begin{array}{l}\text { Comprimento médio } \\
\qquad(\mathrm{cm})\end{array}$ & $\begin{array}{l}\text { Largura média } \\
\qquad(\mathrm{cm})\end{array}$ & $\begin{array}{l}\text { Coeficiente de } \\
\text { variação } \mathrm{C} / \mathrm{L}(\%)\end{array}$ & $\begin{array}{c}\text { Grau de Umidade } \\
(\%)\end{array}$ \\
\hline $1 \mathrm{D}$ & amarelada & 1,02 & 0,39 & $11,43 / 6,27$ & 7,4 \\
\hline $2 \mathrm{~N}$ & creme & 0,98 & 0,36 & $6,83 / 11,06$ & 7,9 \\
\hline $3 \mathrm{D}$ & amarelada & 1,10 & 0,44 & $6,96 / 5,41$ & 7,4 \\
\hline $4 \mathrm{~N}$ & creme & 0,94 & 0,37 & $8,87 / 7,80$ & 7,3 \\
\hline $5 \mathrm{D}$ & amarelada & 1,10 & 0,45 & $4,4 / 8,13$ & 7,6 \\
\hline $6 \mathrm{~N}$ & amarelada & 1,13 & 0,47 & $6,32 / 7,85$ & 7,8 \\
\hline $\mathrm{T}$ & amarelada & 1,00 & 0,42 & $7,41 / 7,86$ & 7,3 \\
\hline
\end{tabular}


número de sementes vazias ou "chochas” deve-se a dois fatores - frutos colhidos antes da total maturação e a influência da estiagem do último ano, que impossibilitou o pleno desenvolvimento dos frutos. Welbaum e Bradford (1989) discutem que a qualidade da semente é tradicionalmente associada ao acúmulo do peso seco máximo, sendo caracterizada pela maturidade fisiológica ou maturidade de massa, isto é, sementes muito jovens, bem como aquelas excessivamente maduras, podem ter sua qualidade comprometida, além de serem mais afetadas pelo tempo de armazenagem. Para Welbaum (1993), a maturação excessiva pode ainda contribuir para o envelhecimento e deterioração das sementes dentro do fruto, ocasionando fissuras no tegumento, podendo resultar em danos ao embrião e lixiviação de solutos, e até mesmo na perda da viabilidade de tais sementes. Tal anormalidade foi detectada apenas no acesso $5 \mathrm{D}$, com um número pequeno de sementes apresentando a característica, sugerindo uma colheita tardia de um ou mais frutos dos quais se retiraram as sementes. Embora não tenha sido possível diagnosticar o período exato de colheita dos melões de cada um dos acessos para extração das sementes, os dados da bibliografia e aqueles apontados pelo mantenedor do acesso $2 \mathrm{~N}$ sugerem que o mesmo tenha ocorrido precocemente. A colheita precoce, influenciada ou não por fatores microclimáticos, pode ser apontada como a principal responsável pelo grande número de sementes vazias ou ‘chochas' do acesso em questão.

Foram diagnosticados diferentes tratamentos dados pelos agricultores às suas sementes antes de armazená-las (Tabela 3). Estabelecendo uma relação com o manejo pós-colheita das sementes e os resultados dos testes sanitários, pode-se observar que a maior parte das práticas utilizadas pelos agricultores se mostraram simples e eficazes. O laudo de diagnóstico sanitário indicou que nenhum dos acessos apresentou contaminação por vírus ou bactérias. Quatro acessos (1D, 3D, 4N, 6N) e a variedade comercial (T) também não apresentaram indícios de contaminação por fungos. Detectou-se a presença de Phoma sp. e Cladosporium sp. para o acesso 2N e Fusarium sp. para o acesso 5D (Tabela 3).

Embora sejam utilizados métodos simples de manejo e havendo a reutilização das sementes, não há evidências da

TABELA2. Valores médios de peso total de sementes (PT), peso de sementes cheias (PC), número total de sementes (NT), número de sementes cheias (NC), percentual de sementes vazias (V), média do peso de 100 sementes (MS), desvio padrão (S), coeficiente de variação (CV) e peso de mil sementes (PMS) obtidos para os seis acessos de sementes de melões crioulos e testemunha (T). UFRGS, Porto Alegre/ RS, 2006.

\begin{tabular}{|c|c|c|c|c|c|c|c|c|c|}
\hline \multirow{2}{*}{ Acesso } & PT & $\mathrm{PC}$ & NT & $\mathrm{NC}$ & V & MS & $\mathrm{S}$ & CV & PMS \\
\hline & (g) & (g) & (u) & (u) & $(\%)$ & (g) & $\therefore$ & $(\%)$ & (g) \\
\hline 1D & 25,97 & 25,8 & 1088 & 1075 & 1,19 & 3,11 & 0,095 & 3,0 & 24,03 \\
\hline $2 \mathrm{~N}$ & 33,65 & 24,1 & 3670 & 878 & 76,07 & 1,45 & 0,077 & 5,3 & 27,51 \\
\hline $3 \mathrm{D}$ & 56,75 & 55,0 & 2020 & 1752 & 13,26 & 2,92 & 0,182 & 6,2 & 31,41 \\
\hline $4 \mathrm{~N}$ & 18,19 & 17,9 & 998 & 930 & 6,81 & 2,07 & 0,056 & 2,7 & 19,24 \\
\hline $5 \mathrm{D}$ & 53,05 & 52,6 & 1557 & 1490 & 4,30 & 3,32 & 0,153 & 4,6 & 35,34 \\
\hline $6 \mathrm{~N}$ & 35,01 & 33,4 & 1176 & 882 & 25,00 & 2,89 & 0,202 & 6,9 & 37,86 \\
\hline $\mathrm{T}$ & 52,31 & 52,3 & 1526 & 1521 & 0,33 & 3,43 & 0,073 & 2,1 & 34,36 \\
\hline
\end{tabular}

TABELA 3. Manejo realizado pelos agricultores e patógenos indentificados nas amostras de sementes de diferentes acessos e testemunha. UFRGS, Porto Alegre/RS, 2006.

\begin{tabular}{|c|c|c|c|}
\hline Acesso & Manejo antes da armazenagem & Armazenagem/ cuidados & $\begin{array}{c}\text { Patógenos identificados } \\
\text { nas amostras }\end{array}$ \\
\hline $1 \mathrm{D}$ & $\begin{array}{l}\text { Seleção. Fermentação na polpa. Higienização com água e } \\
\text { calda sufocálcica. Secagem à sombra. }\end{array}$ & Umidade, temperatura. & 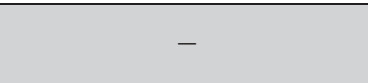 \\
\hline $2 \mathrm{~N}$ & Seleção. Higienização com água. Termoterapia solar. & Umidade, temperatura, luz. & $\begin{array}{l}\text { Phoma sp. e } \\
\text { Cladosporium sp. }\end{array}$ \\
\hline $3 \mathrm{D}$ & Seleção. Higienização com água. Termoterapia solar. & Umidade, temperatura, luz. & - \\
\hline $4 \mathrm{~N}$ & Seleção. Higienização com água. Secagem à sombra & Umidade, temperatura. & - \\
\hline $5 \mathrm{D}$ & Seleção. Higienização com água. Termoterapia solar. & Umidade, temperatura, luz. & Fusarium Sp. \\
\hline $6 \mathrm{~N}$ & Seleção. Higienização com água. Termoterapia solar. & Umidade, temperatura, luz. & \\
\hline $\mathrm{T}$ & $\begin{array}{l}\text { Seleção. Higienização com água. Secagem à sombra, } \\
\text { extração das sementes 'chochas' em câmara de gravidade. }\end{array}$ & Umidade, temperatura, luz. & - \\
\hline
\end{tabular}


presença de microrganismos, na maior parte dos acessos. Em relação à armazenagem realizada pelos agricultores, também se observou a adoção de cuidados referentes a diferentes fatores, como os níveis de umidade, temperatura e luminosidade, limitantes da qualidade das sementes (Bewley e Black, 1986). Os fungos, agentes causais de algumas doenças do meloeiro, podem ser controlados com medidas simples, usadas pela maior parte dos agricultores, como a lavagem cuidadosa das sementes e através da adoção de um período adequado de secagem (à sombra ou ao sol), necessitando o segundo procedimento de um maior cuidado em relação à superexposição solar, o que poderia interferir negativamente na qualidade de tais sementes. Silva e Costa (2003) sugerem, entre outros, o tratamento de sementes de melão através de termoterapia solar para controle de doenças fúngicas como aquela causada por Didymella bryoniae, cujo anamorfo, do gênero Phoma, foi identificado para um dos acessos estudados (Tabela 3). Segundo Machado (2000), a termoterapia é um método não poluente, com ação erradicante de infecções profundas que nem sempre são alcançadas por outras formas de tratamento, embora se refira a possíveis danos à qualidade das sementes que podem ser ocasionados pela termoterapia, indicando a utilização de fungicidas protetores, além de cuidados na superexposição. De acordo com Claro (2001), a calda sufocálcica é inseticida, acaricida e fungicida barato e de baixa toxicidade, que pode ser elaborado na própria propriedade, como realizado pelo agricultor do acesso 1D (Tabela 3). Acredita-se que a calda tenha ação positiva devido ao seu conteúdo rico em cálcio, magnésio, enxofre e microelementos, ativando o processo enzimático e estimulando a proteossíntese (Claro, 2001).

Todos os acessos analisados (Tabela 4) apresentaram germinação superior à mínima estabelecida (80\%) como padrão de sementes fiscalizadas para comercialização de sementes de melão no Estado do Rio Grande do Sul (CESM/ RS, 2000). O acesso 5D se destacou estatisticamente pelos resultados de germinação (G), embora tenha sido um dos dois acessos que apresentaram presença de estruturas características de fungos, o que evidencia a não interferência do microrganismo no desenvolvimento inicial das plântulas. O acesso 3D se destacou quanto à PCG, apresentando 91\% de germinação na primeira contagem. Em relação ao EA, não houve estratificação estatística entre os acessos (Tabela 4). Nos testes de vigor indiretos, ao se determinar o tamanho médio e peso seco total das plântulas, os acessos 5D e 6N se sobressaíram em relação aos demais (Tabela 5).

TABELA4. Valores médios obtidos (\%) nos testes de germinação (G), primeira contagem de germinação (PCG), índice de velocidade de germinação (IVG) e envelhecimento acelerado (EA) - plântulas normais (PN), plântulas anormais (PA) e sementes não germinadas (NG), realizados em seis acessos de melões crioulos mais a testemunha (T). UFRGS, Porto Alegre/ RS, 2006.

\begin{tabular}{|c|c|c|c|c|c|c|}
\hline \multirow{2}{*}{ Acessos } & \multirow{2}{*}{$\mathbf{G}(\%)$} & \multirow{2}{*}{ PCG (\%) } & \multirow{2}{*}{ IVG } & \multicolumn{3}{|c|}{...............................EA............................. } \\
\hline & & & & PN (\%) & $\mathbf{P A}(\%)$ & NG (\%) \\
\hline $1 \mathrm{D}$ & $83 \mathrm{~b}^{*}$ & $67 \mathrm{~cd}$ & $16,304 \mathrm{c}$ & $74 \mathrm{a}$ & $25 \mathrm{a}$ & $1 \mathrm{a}$ \\
\hline $2 \mathrm{~N}$ & $83 \mathrm{~b}$ & $77 \mathrm{bc}$ & $17,294 \mathrm{bc}$ & $76 \mathrm{a}$ & $8 \mathrm{a}$ & $16 \mathrm{a}$ \\
\hline $3 \mathrm{D}$ & $91 \mathrm{ab}$ & $91 \mathrm{a}$ & $18,460 \mathrm{abc}$ & $88 \mathrm{a}$ & 9 a & $3 \mathrm{a}$ \\
\hline $4 \mathrm{~N}$ & $90 \mathrm{ab}$ & $57 \mathrm{~d}$ & $16,474 \mathrm{c}$ & $90 \mathrm{a}$ & 9 a & $1 \mathrm{a}$ \\
\hline $5 \mathrm{D}$ & $97 \mathrm{a}$ & $86 \mathrm{ab}$ & $20,894 \mathrm{ab}$ & $90 \mathrm{a}$ & $9 \mathrm{a}$ & $1 \mathrm{a}$ \\
\hline $6 \mathrm{~N}$ & $90 \mathrm{ab}$ & $88 \mathrm{ab}$ & $21,802 \mathrm{a}$ & $86 \mathrm{a}$ & $11 \mathrm{a}$ & $3 a$ \\
\hline $\mathrm{T}$ & $89 a b$ & $85 \mathrm{ab}$ & $18,492 \mathrm{abc}$ & $74 \mathrm{a}$ & $20 \mathrm{a}$ & $6 \mathrm{a}$ \\
\hline
\end{tabular}

TABELA5.Valores médios obtidos nos testes de vigor (TMH= tamanho médio do hipocótilo hipocótilo; TMR= tamanho médio da raiz; TMP= tamanho médio da plântula; $P S P=$ peso seco da plântula; $P S C=$ peso seco dos cotilédones e $P S T=$ peso seco total) realizados em seis acessos de melões crioulos e testemunha (T). UFRGS, Porto Alegre/ RS, 2006.

\begin{tabular}{ccccccc}
\hline Acessos & TMH $(\mathrm{cm})$ & TMR $(\mathrm{cm})$ & TMP $(\mathrm{cm})$ & PSP $(\mathrm{g})$ & PSC $(\mathrm{g})$ & PST $(\mathrm{g})$ \\
\hline $1 \mathrm{D}$ & $7,04 \mathrm{~b}^{*}$ & $7,42 \mathrm{a}$ & $14,46 \mathrm{ab}$ & $0,14 \mathrm{a}$ & $0,15 \mathrm{bc}$ & $0,29 \mathrm{bcd}$ \\
$2 \mathrm{~N}$ & $8,33 \mathrm{a}$ & $4,84 \mathrm{~b}$ & $13,18 \mathrm{~b}$ & $0,12 \mathrm{a}$ & $0,12 \mathrm{c}$ & $0,23 \mathrm{~cd}$ \\
$3 \mathrm{D}$ & $5,97 \mathrm{c}$ & $6,84 \mathrm{a}$ & $12,81 \mathrm{~b}$ & $0,09 \mathrm{a}$ & $0,22 \mathrm{ab}$ & $0,31 \mathrm{bcd}$ \\
$4 \mathrm{~N}$ & $5,58 \mathrm{bc}$ & $6,30 \mathrm{ab}$ & $12,87 \mathrm{~b}$ & $0,08 \mathrm{a}$ & $0,11 \mathrm{c}$ & $0,19 \mathrm{c}$ \\
$5 \mathrm{D}$ & $7,05 \mathrm{~b}$ & $7,08 \mathrm{a}$ & $14,13 \mathrm{ab}$ & $0,17 \mathrm{a}$ & $0,29 \mathrm{a}$ & $0,46 \mathrm{a}$ \\
$6 \mathrm{~N}$ & $8,10 \mathrm{a}$ & $7,29 \mathrm{a}$ & $15,39 \mathrm{a}$ & $0,15 \mathrm{a}$ & $0,25 \mathrm{a}$ & $0,40 \mathrm{ab}$ \\
$\mathrm{T}$ & $6,44 \mathrm{bc}$ & $6,46 \mathrm{ab}$ & $12,90 \mathrm{bc}$ & $0,11 \mathrm{a}$ & $0,23 \mathrm{ab}$ & $0,35 \mathrm{abc}$ \\
\hline
\end{tabular}

* Médias seguidas de mesma letra na coluna não diferem entre si pelo teste Tukey a 5\% de probabilidade. 
Independente do acesso, forma de beneficiamento e acondicionamento das sementes, verificou-se através dos testes de germinação e vigor realizados, que a qualidade fisiológica das sementes vem sendo mantida. Para Muniz et al. (2004), a análise do potencial fisiológico é um importante componente nos programas de controle de qualidade destinados a garantir um desempenho satisfatório das sementes, havendo ainda uma relação entre este potencial e a qualidade sanitária. De acordo com as RAS (Brasil, 1992), a sanidade da semente refere-se, primariamente, à presença ou ausência de agentes patogênicos, tais como fungos, bactérias, vírus e nematóides. Entretanto, pode também estar relacionada a anomalias decorrentes de alterações nutricionais e condições climáticas adversas, ocorridas no campo, no processamento ou no armazenamento. Assim, é possível que a qualidade sanitária seja otimizada através da reavaliação de técnicas de manejo pós-colheita e armazenamento em casos específicos, através de práticas que aproximem os saberes popular e científico.

O presente estudo, ao avaliar a qualidade física, fisiológica e sanitária das sementes de melões crioulos, busca contribuir à ampliação da discussão sobre a importância e eficácia dos conhecimentos e práticas tradicionais relacionados ao manejo pós-colheita e armazenamento, bem como em relação aos aspectos que podem ser melhorados, além de servir como promotor do uso destas e de outras sementes tradicionais. No entanto, de acordo com Carvalho (2003), as sementes tradicionais possuem múltiplas características que não podem ser apreendidas simplesmente medindo-se o rendimento, por mais importante que ele seja, já que os agricultores familiares têm exigências específicas para suas sementes, segundo o local em que são utilizadas, e não unicamente o alto rendimento prometido em condições controladas. Estas múltiplas variáveis e sistemas de adaptação que os agricultores levam em conta ao escolher, manter e multiplicar suas sementes opõem-se aos procedimentos formais de seleção genética, nos quais as variedades são selecionadas de forma individual por certos fatores isolados e logo são cruzados para combinar esses fatores. Além disso, segundo Jiggins et al. (1996), os ensaios com variedades de alto rendimento em países subsaarianos mostram 'variações maiores', tanto em sementes 'tradicionais' quanto 'melhoradas', entre os agricultores e entre diferentes anos, que as diferenças médias observadas entre sementes 'tradicionais' e 'melhoradas' em um mesmo ano.

A valorização e promoção do uso de variedades adaptadas ao Estado do Rio Grande do Sul poderá contribuir não só em relação à manutenção da variabilidade do germoplasma da espécie, como também para o fortalecimento da agricultura familiar e abastecimento de mercados locais, gerando mais renda, menos impacto ao ambiente e oportunidade de diversificação da produção, garantindo, ainda, a segurança alimentar de muitas famílias. Para isto, é necessário refletir sobre a reestruturação dos pilares de ambos os sistemas de sementes: o formal e o informal. Se a base de todo o sistema formal está no informal, deste depende as sementes comerciais. Para que as variedades tradicionais continuem sendo multiplicadas, as sementes precisam atender, em primeiro lugar, as necessidades estabelecidas pelos agricultores que as mantêm. São estas as prioridades que devem ser levadas em consideração por qualquer sistema de certificação, principalmente quando se trata de um país tão biodiverso quanto o Brasil, em que tais recursos se caracterizam como uma riqueza potencial socioambiental.

A multiplicação de sementes de variedades de melões e outras variedades tradicionais depende hoje de um olhar cuidadoso de todos os envolvidos na questão, a fim de que a qualidade seja o resultado das múltiplas características relevantes aos 'agricultores-sementeiros'.

\section{CONCLUSÕES}

As sementes dos acessos de melões tradicionais apresentaram variações significativas na coloração e dimensões.

Todos os acessos apresentaram mais de $80 \%$ de germinação, independente das condições de manejo póscolheita e armazenamento.

\section{REFERÊNCIAS}

ASSOCIATION OF OFFICIAL SEED ANALYSIS. Seed vigor testing handbook. East Lansing: AOSA, 1983. 88p. (Contribution, 32).

BERNARD, H.R. Research methods in cultural anthropology. Newbury Park: Sage Publications, 1988. 520p.

BEWLEY, J. D; BLACK, M. Seeds: physiology of development and germination. New York: Plenum Press, 1986. 367p.

BRASIL. Ministério da Agricultura e da Reforma Agrária. Regras para análise de sementes. Brasília: SNDA/DNDV/CLAV, 1992. 365p.

CARVALHO, H. M. Sementes: patrimônio do povo a serviço da humanidade. São Paulo: Expressão Popular, 2003. 352p.

CLARO, S.A. Referenciais tecnológicos para a agricultura familiar ecológica: a experiência da Região Centro Serra do Rio Grande do Sul. Porto Alegre: EMATER/RS - ASCAR, 2001. 250 p. 
COMISSÃO ESTADUAL DE SEMENTES DE MUDAS. Normas e padrões de produção de sementes para o estado do Rio Grande do Sul. Porto Alegre: DPV, 2000. 107p.

DOMINGUEZ, O.; PESKE, S.T.; VILLELA, F.A.; BAUDET, L. Sistema informal de sementes: causas, conseqüências e alternativas. Pelotas: UFPel, 2000. 207p.

FAO (Organização das Nações Unidas para Alimentação e Agricultura). Manual para avaliação de plântulas em ensaio de germinação. Roma: ISTA, 1987. 112p.

FERREIRA, A. G; BORGHETTI, F. Germinação: do básico ao aplicado. Porto Alegre: ARTMED, 2004. 323p.

INTERNATIONAL SEED TESTING ASSOCIATION. International rules for seed testing. Zürich: ISTA, 2004. 206p.

JIGGINS, J.; REIJNJETS, C.; LIGHTFOOT, C. Mobilising science and technology to get agriculture moving in Africa: a response to Borlaug and Dowswell. Development Policy Review, London, v.14, n.1, p. 89-103, 1996.

KOKOPELI SEED FOUNDATION. Manual de sementes em português. Disponível em: <http://www.kokopelli-seedfoundation.com/e/index.html>. Acesso em 14 dez. 2005.

MACHADO, J. C. Tratamento de sementes no controle de doenças. Lavras: LAPS/UFLA/FAEPE, 2000. 138 p.

MOHAMED, EL T. I; TAHA YOUSIF, M. Indigenous melons (Cucumis melo L.) in Sudan: a review of their genetic resources and prospects for use as sources of disease and insect resistance. Plant Genetic Resources Newsletter, Italy, v.138, p. 38-42, 2004.

MUNIZ, M. F. B; GONÇALVES, N; GARCIA, D. C; MARISKULCZYNSKI, S. Comparação entre métodos para avaliação da qualidade fisiológica e sanitária de sementes de melão. Revista Brasileira de Sementes, Pelotas, v. 26, n. 2, p. 144149, 2004.

PITRAT, M.; HANELT, P.; HAMMER K. Some comments on interespecific classification of cultivars of melon. Acta Horticulturae, Belgium, v. 510, p. 29-36, 2000.

QUIST, D.; CHAPELA, I. H. Transgenic DNA introgressed into traditional maize landraces in Oaxaca, México. Disponível em: <http://contanatura.weblog.com.pt/arquivo/2004/10/ download_file.html>. Acesso em 22 mar. 2006.

SILVA, H. R; COSTA, N. D. Melão. Produção. Aspectos Técnicos. Brasília: Embrapa Informação Tecnológica, 2003. 144p.

TAVARES, S. H. C. C. Melão. Fitossanidade. Brasília: Embrapa Informação Tecnológica, 2002. 87p.

TORRES, S. B. Métodos para avaliação do potencial fisiológico de sementes de melão. 2002. 103f. Tese (Doutorado em Agronomia) - Escola Superior de Agricultura “Luiz de Queiroz”, Universidade de São Paulo, Piracicaba, 2002.

VIEIRA, R. D.; CARVALHO, N. M. Testes de vigor em sementes. Jaboticabal: FUNEP/UNESP, 1994. 164 p.

WELBAUM, G.E.; BRADFORD, K.J. Water relations of seed development and germination in muskmelon (Cucumis melo L.). II. Development of germinability, vigour, and desication tolerance. Journal of Experimental Botany, California, v. 40, p. 1355-1362, 1989.

WELBAUM, G.E. Water relations of seed development and germination in muskmelon (Cucumis melo L.). VIII. Development of osmotically distended seeds. Journal of Experimental Botany, California, v.44, p. 1245-1252, 1993. 